Regular Research Article

\title{
Improving food security? Setting indicators and observing change of rural household in Central Sulawesi
}

\author{
Dewi Nur Asih ${ }^{1, *}$, Stephan Klasen ${ }^{2}$ \\ 1 Tadulako University. Email: dewi.nurasih5@gmail.com \\ 2 University of Göttingen. Email: sklasen@uni-goettingen.de \\ * Corresponding author
}

\begin{abstract}
Household food security is a critical issue for Indonesia, which is investigated in this study. Many of rural household in Indonesia depends on agricultural sectors and facing challenges of global warming that threatening food security and poverty alleviation in the country. We use panel data at the household level for a sample of households living in Central Sulawesi at the rainforest margin in Indonesia. For the purpose of this study, we apply principal component analysis to develop an indicator of food security and used the index in determining the household's condition to be persistent food secure or insecure. The findings present the fact that over the period the household's food security in the study area has changed to better food condition. The number of people who are food insecure has declined by $23.73 \%$ over the year. However, the results suggest that public services on health, education and infrastructure need to be strengthened, investments in access to credit and off-farm employment policies, as well as insurance programs on social protection and disaster management, need to be developed.
\end{abstract}

Keywords: food security; rural households; Indonesia

\section{Introduction}

Food security is a broad concept in which the main goal is for all individuals to have an adequate level of food at all times and to be able to utilize the food to meet increasing consumption demand. Food security exist when all people, at all times, have physical and economic access to sufficient, safe, and nutritious food, enabling them to meet their dietary needs and food preferences for an active and healthy life (FAO, 1996). According to the definition, there are four main dimensions of food security: food availability, food accessibility, food utilization, and food system stability or affordability, which all need to be met in order to properly address the food security problem.

All dimensions of food security are at great risk due to climate change. According to projections by the Intergovernmental Panel on Climate Change (IPPC), global temperatures could increase by $4^{\circ} \mathrm{C}$ or more above mid-18th-century levels by 2100 , which combined with increasing food demand, would pose large risks to food security, both globally and regionally. All aspects of food security are potentially affected with projected reductions in food supplies, income, and employment (IPCC, 2014). Climate-induced changes in agricultural productivity can occur through crop failure, new patterns of pests and diseases, lack of appropriate seeds and planting material, and the loss of livestock, which can all lead to a reduction in food production (FAO, 2008). This will threaten food production, income and become a main factor-influencing household's capability to ensure their food security.

Indonesia is likely to be affected by the challenges that accompany global warming, such as increasing temperatures, intense rainfall, and rising sea levels, which will threaten food security and poverty alleviation (Measey, 2010). Indonesia classified by the World Bank as a lower middle-income country, has experienced significant economic growth in recent decades. Since the economic crisis of 1997-98, the GNI per capita of the country increased steadily from $\$ 560$ (using 
market exchange rates) in the year 2000 to $\$ 3,650$ in 2014, and the country was successful in improving macroeconomic stability. This includes a significant drop in the Debt-to-GDP ratio from 61 to 24 percent from the year 2003 to 2014 (World Bank, 2015). Indonesia is also the fifth most populous country in the world with a total population of 254.5 million. Most of this population lives in rural areas and depends on agriculture for their income and livelihood. The agricultural sector makes up the second largest share of GDP of the country, accounting for 15.30 percent of total GDP, which employs 40 percent of all rural workers (Netherlands Commission for Environmental Assessment, 2015; Food Security Council and WFP, 2015). The workers engaged in the agricultural sectors, which are already faced with climatic challenges. Therefore, any irregularities in climate patterns may lead to serious consequences and pose serious problems to agricultural production as well as the growth and development of the country.

Considering millions of poor households in the rural areas of Indonesia are dependent on agriculture, these adverse conditions can have substantial negative effects on income and food security through problems associated with agricultural production that will threaten individual and household welfare in the country. Therefore, the aim of this study is to highlight the vulnerability of the food security problem in rural areas in Indonesia.

\section{Materials and Methods}

\subsection{Data}

This study uses three-year panel data collected in 2001, 2004 and 2006 in Central Sulawesi. The surveys covered a sample of 261 households for each year, selected randomly from 13 different villages in the vicinity of the Lore Lindu National Park in Central Sulawesi, Indonesia. Most of these households comprise small-scale farmers with rain-fed farms, which more than 60 percent of Indonesians farmers fall into this category. In addition, the main source of data on socio-economic factors with attributes to the regions and the country comes from the Central Bureau of Statistics, which collates data from ministerial and non-ministerial departments.

\subsection{Analysis}

To establish the food security status of the rural households we constructed a food security index (FSI). A time-variant household food security was developed from Principal Component Analysis (PCA), where we correlated the amount of the total production of the farming households, total household income and the amount of land value of the households that we assumed could present an indicator of food security availability, access and stability.

Principal Component Analysis is a type of factor analysis, based on a statistical technique used to reduce the given number of variables, by extracting a linear combination, which best describes these variables and then transforms them into one index (Cavatassi et al, 2004; Vyas and Kumaranayake, 2006). The first principal component is the linear combination, capturing the greatest variation among the set of variables; it can be converted into factor scores, which serve as weights for the creation of the marginality index (Cavatassi et al, 2004). Stated mathematically, from an initial set of $\mathrm{n}$ correlated variables, PCA creates uncorrelated indices or components, whereby each component is a linear weighted combination of the initial variables. For example, from a set of variables $X_{1}$ through to $X_{n}$, as follows:

$$
P C_{m}=a m_{1} X_{1}+a m_{2} X_{2}+a m_{3} X_{3}+\ldots+a m_{n} X_{n}
$$

where :

$a_{m n}$ represents the weight for the $m_{\text {th }}$ principal component

$\mathrm{n}_{\mathrm{th}}$ variable, which are the weights of the respective food security variables identified.

$X_{1}, X_{2}, \ldots X_{n}$, are the food security-related variables that we will use (i.e. food production, cash crop and off-farm income and land value, see the equation below). 
The first component explains the largest amount of variance in the given data, subject to the constraint where the sum of the squared weights is equal to one. However, as the first principal component is expressed in terms of the original (non-normalized) variables, the food security index for each household is then derived based on the formula from Filmer and Pritchett (1998) as follows:

$$
\begin{aligned}
\mathrm{FS}_{\mathrm{j}} & =\mathrm{F} 1\left(\mathrm{X}_{\mathrm{j}} 1-\mathrm{X} 1\right) / \mathrm{S} 1 \ldots \mathrm{FN}\left(\mathrm{X}_{\mathrm{j}} \mathrm{N}-\mathrm{XN}\right) / \mathrm{SN} \text {; or } \\
\mathrm{FSI}_{\mathrm{j}} & =\sum \mathrm{F}_{\mathrm{i}}\left[\left(\mathrm{X}_{\mathrm{ij}}-\mathrm{X}_{\mathrm{i}} / \mathrm{SiO}\right] \ldots \ldots \ldots \ldots \ldots \ldots \ldots \ldots \ldots \ldots \ldots \ldots \ldots \ldots \ldots \ldots \ldots \ldots\right.
\end{aligned}
$$

$\mathrm{FSI}_{\mathrm{j}}$ is the food security index and follows a normal distribution mean of 0 and a standard deviation of 1 . Fi is the weight of the $i_{\text {th }}$ variable in the PCA model. $X_{i j}$ is the $j_{\text {th }}$ household's value of the $i_{\text {th }}$ variable. $X i$ and $\mathrm{Si}$ are the mean and standard deviations of the $i_{h}$ variable for all households. In line with the discussion above, we will build an index of food security focusing on the three dimensions in terms of the availability, accessibility and the stability of food.

\section{Results and Discussion}

\subsection{Indicator food security}

The availability of food is one indicator of food security. As a proxy for this availability, we use farmers' production of food, i.e. the ability of farmers to directly meet their food security needs through their own food production, which on average accounted for 369,931 IDR per capita (Table 2). As shown in Figure 1, the main cultivated crops in the research area are perennial, annual, vegetable, fruit and others types of crops. Almost $40 \%$ of total production comes from the perennial crops cultivation, whereas cash crops, such as cocoa, are the main crop cultivated by $28 \%$ of the farmers contributing the biggest share to the total crop production (Figure1). Those cash crops that do not directly provide for food needs are not considered in this dimension of food security. On the other hand, annual crop cultivation accounted for $60.00 \%$ of the total crops production, whereas rice as a staple food has a share of $19.47 \%$, followed by maize and vegetables, which contribute $11.74 \%$ and $10.45 \%$ respectively.
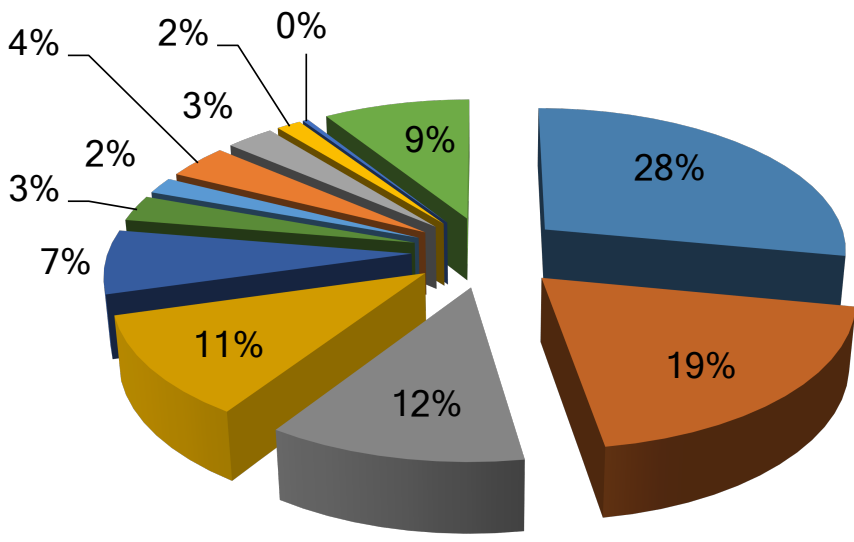

Source: Author Calculation from Survey Data

$\square$ Cocoa
$\square$ Rice
$\square$ Maize
$\square$ Coffee
$\square$ Cassava
$\square$ Peanut
$\square$ Beans
$\square$ Bananas
$\square$ Coconut
$\square$ Mangoes
$\square$ Avocados

Avocados

Figure 1. Crops Cultivated in the research areas

Another important indicator of food security is access to food, which could be a proxy by measuring the ability of households to generate income to procure sufficient food. Included in this 
income is the value of cash crop production, as well as non-farm incomes, both of which can be used to access food indirectly through markets. Food production, which is often included in income calculations, is not included here as it is already covered in the dimension of availability and reflects direct access to food. Figure 2 shows food accessibility of the household measured through agricultural income from cash crops (cocoa and coffee cultivation), from renting the land and from agricultural wage employment. While non-agricultural income may derive from pensions, government subsidies, NGO help etc. as well as incoming private remittances. On average, households earned 572,061 IDR/month, where cash crops and non-farm income contributed $171,717 \mathrm{IDR} /$ month and $309,983 \mathrm{IDR} /$ month respectively to the total household income (Figure 2). Income is thus expected to increase a household's accessibility to a larger quantity of food and better quality food. Therefore, it has positive effects on food security.

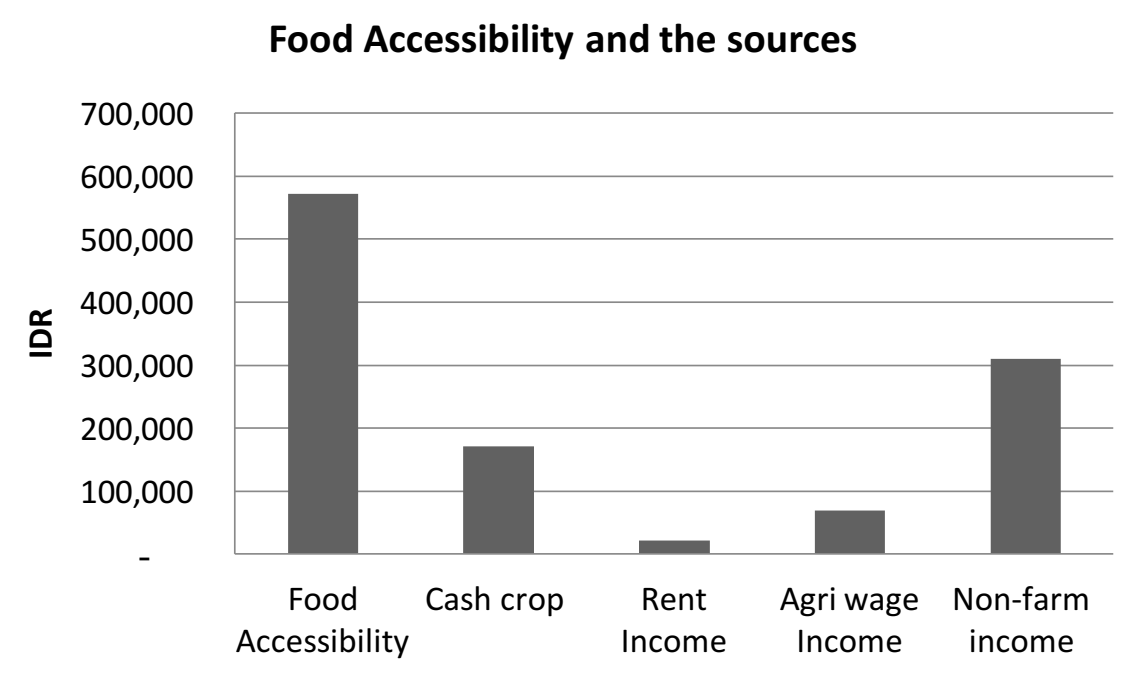

Source: Author calculation from survey data

Figure 2. Household food accessibility and the sources

Total Land Owned

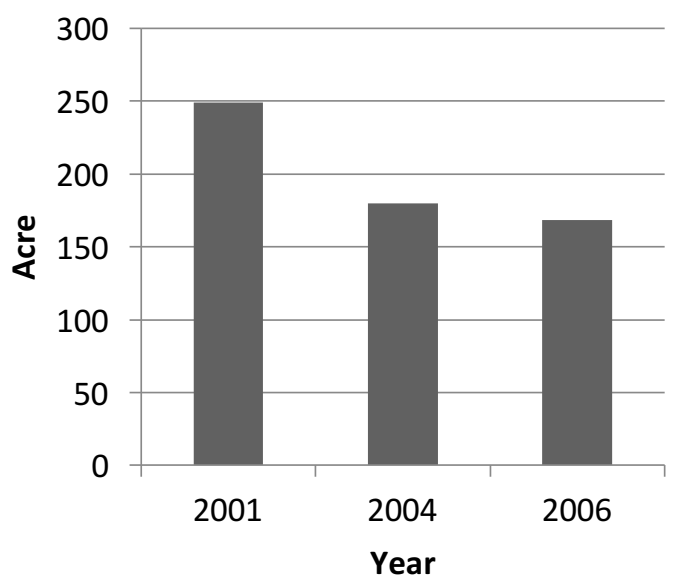

Total Value Land Owned

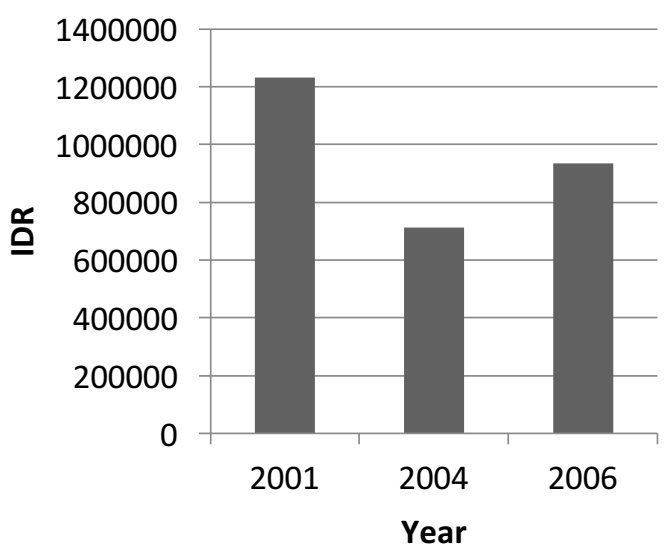

Source: Author calculation from survey data

Figure 3. Total area owned and the value of area owned in $2001-2006$ 
The stability of food refers to the stability of food availability and access to food over time. This is in line with Gregory et al (2005); FAO, (1996); Kuwornu et al., (2011) which states that food system stability or affordability refers to the continuous supply of adequate food at all times without shortages as the key element to preventing post-harvest losses. To be food secure requires a household to have access to adequate food at all times. It means people should have the capability of coping with unexpected food crisis conditions brought on by sudden shocks (e.g. an economic or climatic crisis) or cyclical events (e.g., seasonal insecurity). As such, food security not only includes the availability of food, but also the accessibility and stability of food, as well as the sustainability of the production system. It is not easy to find proxies for stability, but one important foundation of food stability is productive assets. As most respondents in the research area are small-scale farmers, land-holding becomes the most important source in ensuring the continuous supply and demand of food production as well as in generating income and food. Thus, we use the value of land-holding as a proxy to measure food stability of the sample households.

The average land holding per household has declined from 248.92 to 168.22 acre during the years 2001-2006, with the total cultivated area being on average 209.43 acre (Figure 3). This land holding declined by $31.82 \%$ during the years 2001 to 2006 . This implies the important role of land holding, and how it can be a proxy for the capacity to bear risk, grow food and earn income. Therefore, we consider the possibility that food stability will be influenced through the land value of farming households.

\subsection{Principal Component Analysis}

The food security index derived from the principal component analysis is presented in Table 1. The results show that the PCA is able to explain $41.83 \%$ of the variation in food security using the first component. This implies that the model was adequate in explaining the food security status of rural households and that all the three components have a positive correlation with the food security hypothesized. Hence, the first component is considered to be the index of food security of the households. This captures the greatest information from the given variables. The value of the Kaiser Meyer Olkin (KMO) measures of sampling adequacy is 0.5365 , indicating a $53 \%$ level of correlation between the pairs of components, which can be explained by the other variables in the index (Table 1).

Table 1. Summary statistics (Mean) and component loading food security indicators

\begin{tabular}{lcc}
\hline \multicolumn{1}{c}{ Indicator of food security } & Mean & Component loading \\
\hline Availability (IDR) & 369,931 & 0.5911 \\
& $(778,372)$ & \\
Accessibility (IDR) & 575,457 & 0.4742 \\
& $(920,079)$ & \\
Stability (IDR) & 980,793 & 0.6525 \\
& $(1,543,815)$ & \\
\hline
\end{tabular}

\begin{tabular}{ll}
\hline Proportion variation explained & $=0.4183$ \\
KMO & $=0.5365$ \\
Number observation & $=771$
\end{tabular}

Source: Author's calculation from the survey data, Monetary values in real Indonesia rupiah with base year 2001 and provincial CPIs for Palu. Incomes are monthly.

\section{Discussion}

From the three indicators of food security, the component loading shows that all three variables, food production, cash crop and non-farm income and land value are significant in explaining the variations in food security in the study areas with positive signs as expected. We tested this correlation of the food security index over the indicators through the Pearson 
correlation analysis. This was conducted to determine to what extent the food security index correlates with the indicators. Table 2 shows the results of a strong correlation between the component and the index, given the positive sign of Pearson's analysis $(|r|>.5)$. From the results, the availability and stability of food presented by food production and the total value of land owned, are the most important and significant components for the food security of the households. The correlation coefficient $(r, 0.6621$ and 0.7309$)$ was significant at the $1 \%$ level. This is followed by the component accessibility of food (represented by the value of cash crops and non-farm income) with the correlation $r, 0.5312$, statistically significant at $1 \%$ (Table 2 ).

Table 2. Correlation of food security index and the components

\begin{tabular}{lcccc}
\hline \multirow{2}{*}{ Variable } & Food Security & Availability & Accessibility & Stability \\
\cline { 2 - 5 } & $(1)$ & $(2)$ & $(3)$ & $(4)$ \\
\hline Food Security & 1 & 0 & 0 & 0 \\
Availability & $0.6621^{*}$ & 1 & 0 & 0 \\
Accessibility & $0.5312^{*}$ & 0.0801 & 1 & 0 \\
Stability & $0.7309^{*}$ & $0.1952^{*}$ & $0.1769^{*}$ & 0 \\
\hline
\end{tabular}

Source: Author's calculation from the survey data, correlation coefficient at $1 \%$ significant level

This indicates that all of the variables used to capture the variance of the food security indicator are reliable and interconnected with each other. The result is in full conformity with prior expectations, indicating that food production, cash crops, and non-farm income, as well as land value, represent important complementary dimensions of household food security. Interestingly, availability and accessibility are only weakly correlated, suggesting that doing well in one of the indicators does not imply that one is doing well in the other. Based on the PCA result and after normalizing the food security index, we used the mean from the index in determining the cut-off point of the household in our study area to be fall in secure or insecure food over time. We categorized households to be food secure for those who have a positive index value and food insecure otherwise. Overall, the results suggest that food insecurity levels have changed over the three years (Figure 4).

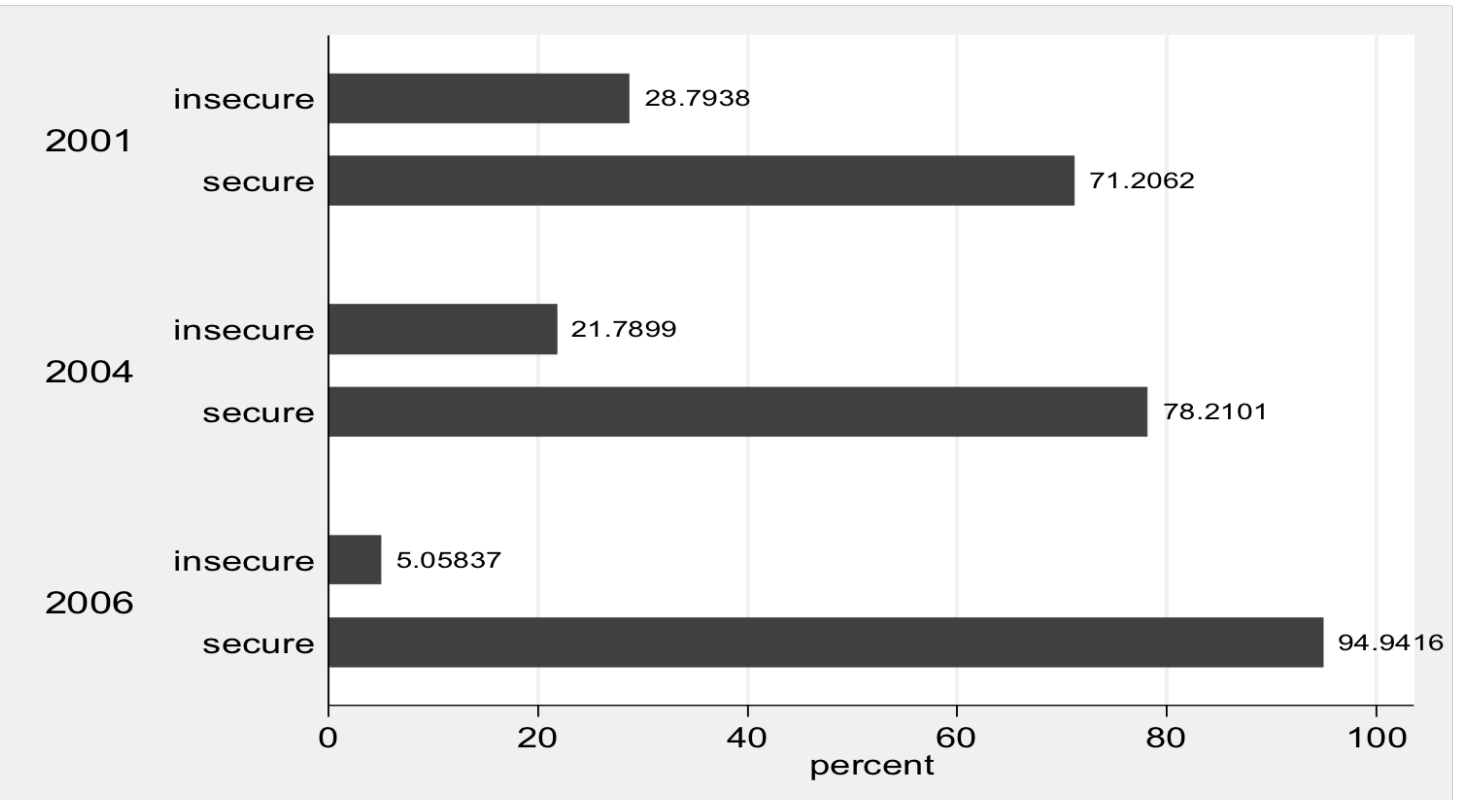

Source: Author's calculation from the survey data

Figure 4. Status food security of the households in Central Sulawesi, Indonesia 
The pattern shows that household food security rose gradually, with 628 households standing in better food condition, increasing from just above $70 \%$ to $90 \%$ over the period of study (Figure 4). This is associated with the increasing food security of the household throughout the period. This was experienced by 61 of the households that have experienced better food conditions. On the other hand the number of people who are food insecure has declined by $23.73 \%$ over the year (Table 3).

Table 3. Food Security and the distributions

\begin{tabular}{lcccc}
\hline Variables & \multicolumn{5}{c}{ Year } \\
\cline { 2 - 5 } & Pooled & 2001 & 2004 & 2006 \\
& $(\mathrm{~N})$ & $(\mathrm{N})$ & $(\mathrm{N})$ & $(\mathrm{N})$ \\
\hline Secure & 628 & 183 & 201 & 244 \\
& $(81.45)$ & $(71.21)$ & $(78.21)$ & $(94.94)$ \\
Insecure & 143 & 74 & 56 & 13 \\
& $(18.55)$ & $(28.79)$ & $(21.79)$ & $(5.06)$ \\
\hline $\mathrm{N}$ & 771 & 257 & 257 & 257 \\
\hline
\end{tabular}

Source: Author's calculation from the survey data. Percentage is in parentheses.

\section{Conclusion}

The results indicate that over the periods (2001-2006), the sample household's food security in the areas studied have changed towards better food conditions. The number of people who are food insecure has declined by $23.73 \%$ over the year. However, the results suggest that public services concerning health, education and infrastructure need to be strengthened. In particular investment in access to credit and off-farm employment policies, as well as insurance programs on social protection and disaster management, need to be developed to help mitigate these problems.

The limitation of this study is the used of the panel data households for 2001, 2004, and 2006, in measuring the food security condition of the households. We used this result in order to combine with the further research when we compare food security of the rural households over the periods with their current food security condition.

\section{References}

Cavatassi, R., Davis B., \& Lipper, L. (2004). Estimating poverty over time and space: construction of a time-variant poverty index for CostaRica. Working Papers 04-21, Agricultural and Development Economics Division, FAO-ESA

Food and Agriculture Organization. (1996). Food Security: Policy Brief. Available at : http://www.fao.org/forestry/13128-0e6f36f27e0091055bec28ebe830f46b3.pdf

Food and Agriculture Organization. (2008). Climate Change And Food Security: A Framework Document. Food and Agriculture Organization Of The United Nations, Rome.

Food Security Council and WFP., 2015. Food Security and Vulnerability Atlas of Indonesia 2015. Jakarta.

Gregory, P., Ingram, J.S.I., \& Brklacich, M. (2005). Climate Change and Food Security. Philosophical Transactions of the Royal Society B-Biological Sciences, 360 (1463): 2139-2148.

Intergovernmental Panel on Climate Change. (2014). Summary for policymakers. In: Climate Change 2014: Impacts, Adaptation, and Vulnerability. Part A: Global and Sectoral Aspects. The contribution of Working Group II to the Fifth Assessment Report of the Intergovernmental Panel on Climate Change [Field, C.B., V.R. Barros, D.J. Dokken, K.J. Mach, M.D. Mastrandrea, T.E. Bilir, M. Chatterjee, K.L. Ebi, Y.O. Estrada, R.C. Genova, B. Girma, E.S. Kissel, A.N. Levy, S. MacCracken, P.R. Mastrandrea, and L.L. White (eds.)]. Cambridge University Press, Cambridge, United Kingdom and New York, NY, USA, pp. 1-32. 
Kuwornu, J.K.M., Mensah-Bonsu, A., \& Ibrahim, H. (2011). Analysis of Foodstuff Price Volatility in Ghana: Implications for Food Security. European Journal of Business and Management 3 (4.): $100-118$

Measey, M. (2010). Indonesia: A Vulnerable Country in the Face of Climate Change". Global Majority E-Journal, 1(1), 31-45.

Netherlands Commission for Environmental Assessment. (2015). Climate change profile Indonesia. The report in a cooperation between the Netherlands Ministry of Foreign Affairs (MFA), Ms. K. Warner and Mr. P. van de Logt (IGG) the Centre for Development Innovation (CDI) of Wageningen UR, Ms. M. Brouwer and Mr. A.J. van Bodegom the Netherlands Water Partnership (NWP), The Netherlands.

Vyas \& Lilani, K. (2006). Constructing Socio-Economic Status Indices: How To Use Principal Components Analysis. The London School of Hygiene and Tropical Medicine, Oxford University Press.

World Bank. (2015). Country Data for Indonesia. Available at: http://www.worldbank.org/en/country/indonesia/overview 